\title{
The comparative experiment of the speed control circuit that adopts the throttle valve and the flow regulating valve
}

\author{
Lijuan Wang \\ Zhengzhou University of Industrial Technology , Henan 451150, China \\ wlj.wh@163.com
}

Keywords: throttle, flow regulating valve, Speed control circuit

\begin{abstract}
Through the contrast experiment that in the adjustable speed loop respectively adopt the throttle and one-way flow regulating valve, record the hydraulic cylinder of a full range of motion on a load and no load cases, and opening size different situations. Then analysis and test and verify time of hydraulic components in the loop, the role and their functions and the structures.
\end{abstract}

\section{Introduction}

At present, in the actual production process, the hydraulic system can provide larger driving force and motion transmission balance, uniform, reliable and easy to control, so it is widely used in various types of machine tool equipment. In the hydraulic system of the machine tool, the core problem is the problem of speed control, and one of the greatest advantages of the hydraulic system is that it is convenient to realize the stepless speed regulation.

In the hydraulic system, the implementation of components of the speed is supplied by the implementation of components of the liquid flow and role in the implementation of components (such as hydraulic cylinder piston) on the effective working area to decide. The general implementation of the components of the effective working area in the running process of the system can not be changed. Therefore, to control the velocity of actuators, generally only to by changing the input of hydraulic cylinder flow way.

There are many methods to adjust the speed, but the hydraulic throttle control unit power with its light weight can be easy to realize stepless speed regulation in short start-up time, and it is convenient to operate, low cost and wide application. The throttle back to the oil, the oil inlet, the bypass throttle speed regulation of three, this my courtyard $\mathrm{TH}$, combined with laboratory experiment of hydraulic equipment, were designed using the throttle valve, the oil return throttling speed control circuit of speed control valve, installed in the hydraulic experiment table, the connection and debugging to Run all the way, and calculate all kinds of throttle valve, utilizing experimental data (recorded from the hydraulic cylinder motion time and speed control valve through flow area corresponding to the piston velocity) and comparative analysis of throttle valve and speed control valve used in the loop, the benefit of different.

The throttle valve is to regulate and control the size of the valve opening directly limit the passage of fluid flow to throttle the. Due to the forced blocked throttle, so before and after the throttle will produce larger pressure difference, controlled fluid pressure loss is relatively large. That is to say after the throttle pressure can be reduced.Speed control valve, which is on the basis of the principle of the throttle and the internal structure of the valve added a pressure compensation device, improve the throttle pressure loss of the phenomenon, the throttle fluid pressure basically equivalent to before throttling pressure, and reduce the flow of the fever.General at a two-way control valve and three-way control valve control valve, two-way control valve is by a fixed differential pressure reducing valve and a throttle valve which are connected in series, three-way control valve is by a constant difference overflow valve and a throttle valve in parallel composition, but they all have a common characteristic: namely, to maintain the section inlet valve, a oil port of the pressure difference constant, so that flow through the throttle valve only and the valve port to open a relevant and load pressure fluctuation has nothing to do. 
Control valve seemingly also called compensation valve. Throttle valve, like a faucet, you twist the big water flow more, but because of the high pressure in the pipeline under the screw tap the same number of turns, water flow, pressure small water flow less. But speed regulating valve is not no matter whether the pipeline pressure is high (relative) in the screw tap the same number of turns, water.Regulating valve is a pressure compensated valve. It has fixed differential reducing valve and throttle valve in series. In front of the throttle valve, pressure P2 and P3 respectively leads to the valve spool right, left ends, when the increase in load pressure P3, decompression valve core is arranged on the left side of the liquid pressure, valve is shifted to the right, decompression population increase, pressure drop decreases, P2 increases envoys valve differential pressure remained unchanged; and vice versa. This is the constant speed control valve flow invariant (is not influenced by load).

\section{Experimental device and return oil throttle speed control circuit design}

Curve in throttling speed control circuit, the throttle valve and the control valve. The two speed load characteristics and speed stiffness has a great difference, which in many hydraulic transmission teaching materials are made a detailed analysis and comparison. In order to qualitatively compare the differences, there often is a graph in the textbooks to describe the speed - load characteristic curve. The author thinks the figure in the speed control valve and the throttle valve curve is not in the same flow section of the orifice of AV precondition. They lose the comparative significance, even will cause some misunderstanding for beginners.

We use a company TH hydraulic transmission experimental equipment, with a quick connector of the hydraulic hose, respectively, to access the throttle valve, speed control valve to form an oil return throttle speed loop.

Throttle return throttle control circuit, as shown in Figure.
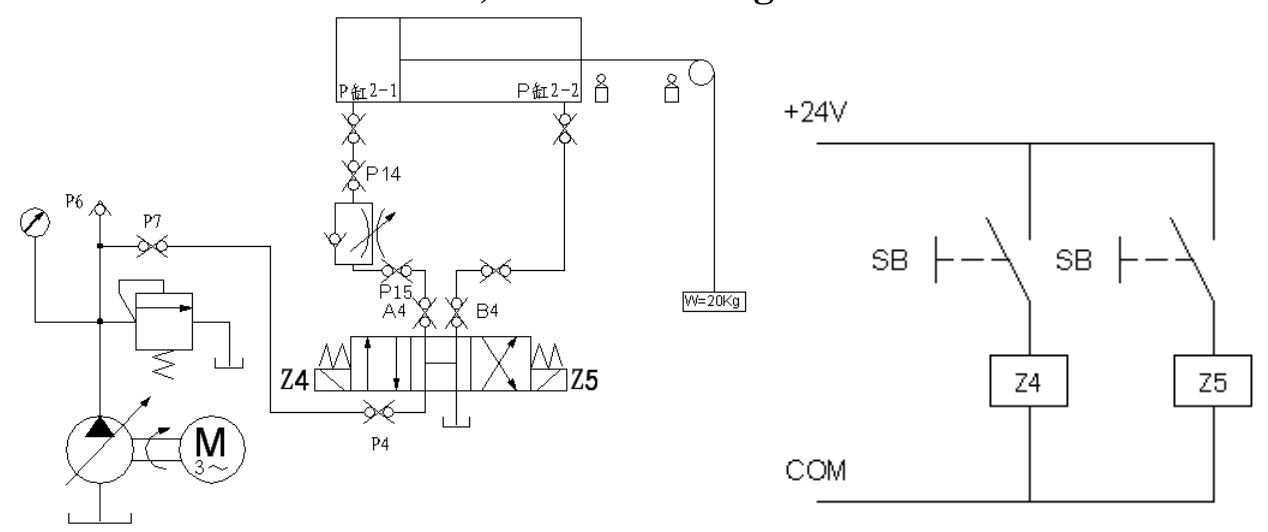

Oil path section

Electrical control part

1) In the case of disconnect the P7 connector, adjust the relief valve (with the relief valve pump source), determine the export pressure of $\mathrm{P}$ for a certain value;

2) Solenoid directional valve $Z 5$ was electric, cylinder two piston rod with a load rise, when the middle of the valve, the electromagnetic valve Z5 lost power, the cylinder two under the action of heavy;

3) Z4 get electric throttle valve, cylinder two with load (no load), the record cylinder full stroke movement time;

4) Adjust the opening of the throttle valve, and record the cylinder movement time, respectively. One way speed control valve back to the throttle control circuit, as shown in Figure. 


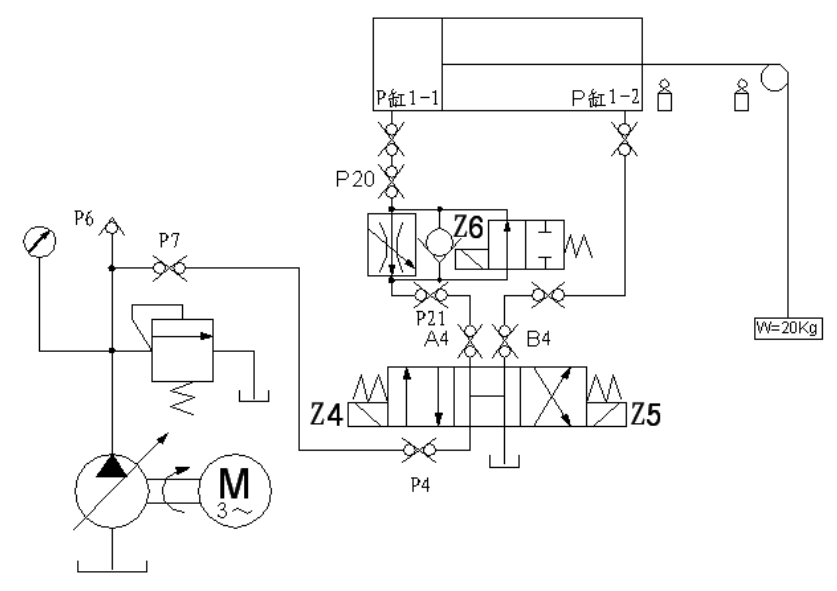

Oil path section

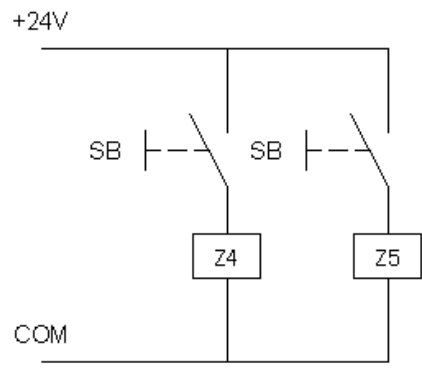

Electrical control part

1) In the case of disconnect the P7 connector, adjust the relief valve (with the relief valve pump source), determine the export pressure of $\mathrm{P}$ for a certain value;

2) Solenoid valve Z5, two cylinder piston rod rises, the Z4 was electric, the piston rod down, regulating one-way speed regulating valve opening were recorded time cylinder motion, and on a one-way throttle valve opening, oil cylinder and two with load and without load of hydraulic cylinder motion time.

\section{Summary}

Through the experimental results and the comparative analysis, we can draw the following conclusions.

(1) If use the throttle, speed load characteristics are poor, and effect of larger, speed stability is not high. The fundamental reason is that the throttle valve can not be a stable valve before and after the pressure difference at the two ends. When the load changes, it will cause difference of the throttle valve before and after the work pressure. For opening a certain amount of throttle valve, according to the formula of orifice flow, when the working pressure changes, flow through the valve will change, which led to the hydraulic execution element motion speed instability.

(2) The speed control valve, loop steady speed greatly improved. This is due to the speed control valve working pressure difference exceeds the minimum pressure difference (usually $0.4 \sim 0.5 \mathrm{MPa}$ ), fluid through the control valve in the throttle valve before and after both ends of the pressure difference is a certain value. Along with the change of load, flow through the speed regulating valve will not change with the pressure difference. Speed stability of the loop is greatly increased.

(3) The speed control valve circuit power loss will be greater than the throttle valve loop power loss, and efficiency is relatively low, which is due to the speed regulating valve is determined by differential type pressure reducing valve and throttle valve composition, the control valve throttle governing circuit exists the overflow loss and throttling loss. So the use of speed control valve throttle governing circuit is used in machine tool feed system for low-voltage small power, such as combination machine tool hydraulic sliding table system, hydraulic turret lathe and hydraulic cutter semi-automatic lathe.

\section{References}

[1] Wei Tong, Shudao Liu. Experimental research on the speed start characteristic of hydraulic throttle speed regulation loop[J]. Machine development, No.4, 1999.

[2] Emin Li. Comparison on Speed-load Characteristic of Speed Regulation Circuit with Throttle Valve and with Flow control Valve. Hydraulic and pneumatic[J], 2005.

[3] Zhenjun Li, Jianying Liu. Hydraulic drive and control [M]. Beijing: China machine Press,2009. 
[4] Jiandong Cao, Xiaoxin Gong. Hydraulic transmission and pneumatic technology[M]. Beijing:Peking University press,2012.

[5] Jun Du,Tangchun Zhao. Speed load characteristic analysis of throttle speed control circuit[J]. Mechanical management and development, 2009.

[6] Kunmin Zhou, Shaogang Hu. Modeling and dynamic characteristics of throttle speed regulation system[J]. Journal of Changzhou Institute of Technology,2006.

[7] Qionhe Gao,Sunan Wang.Computer simulation of hydraulic circuit of throttle valve timing based on MATLAB[J].Machine tools and hydraulic.2006.

[8] Mingxin Jia.Hydraulic drive and control[M].Beijing:National Defence Industry Press,2001.

[9] Shuo Li,Danjun Shao.Research on speed and load characteristics of inlet throttle of throttle valve and speed control valve[J].Hydraulics Pneumatics \& Seals,2010.

[10]Zhihong Li,Jiwen Chen.Research on dynamic characteristics of load change of inlet throttle speed control system based on speed regulating valve[J].Journal of Hunan University of Technology,2010. 